\title{
MEMÓRIA, LINGUAGEM E HISTÓRIA NO FESTIVAL NATIVISTA
}

\author{
Elizabeth Fontoura Dorneles
}

\begin{abstract}
RESUMO: The text introduces reflections about memory. We try to discover wich is the relation between collective memory and discursive memory. In this sense, we have conceptions of history and Discourse Analysis $(A D)$. We guide the analysis about the way how work the construction of "gaúcha" memory, at the Nativistc Festivals.
\end{abstract}

PALAVRAS-CHAVE: memória, história, arquivo, lembrança, esquecimento, festivais nativistas

\section{INTRODUÇÃO}

A proposta de trabalhar com memória leva-nos a explicitar concepções que perpassam nossas inquietações. Dessa forma, definimos que nosso trabalho afasta-se da conceituação de memória enquanto função biopsicofisiológica, uma vez que os campos de estudo que se associam no

Elizabeth Fontoura Dorneles é professora da UERGS e do Departamento de Artes, Comunicação e Letras da UNICRUZ, mestre em Letras, com concentração em Teorias do Texto e do Discurso, pelo PPGL da UFRGS. Doutorando no mesmo programa. E-mail: dorneles@comnet.com.br 
contexto investigatório que nos situamos distanciam-se dessas áreas. Nesse sentido, os fundamentos que sustentam nossas reflexões acerca da memória tomam a questão numa perspectiva delineada em Le Goff (1996, p. 423 - 483), ou seja, eles serão direcionados para a esfera das ciências sociais e humanas. E assim que tomamos a memória como objeto empírico de investigação. A partir de tal enfoque, nos encaminhamos para pesquisas onde resgate da memória poderá ser entendido como (re)construção histórica que se efetua pelo gesto analítico sobre o arquivo.

É necessário também dizer aqui que arquivo para nós tem dois sentidos. Com Pêcheux (1994, p.54), estamos definindo, num primeiro sentido, arquivo entendido no seu sentido amplo de campo de documentos pertinentes e disponíveis sobre uma questão e, num segundo, arquivo se constitui como efeito do gesto analítico, através do qual se dá o trabalho sobre a plurivocidade de sentido. Arquivo agora resulta de uma construção onde a interpretação constitui a materialidade que é acolhida como corpus de análise.

História e memória são vistas muitas vezes como sinônimas. Nós não as entendemos assim visto que a história é a forma científica da memória e memória é o que fica do passado, o que se mantém como vivido e que é dado a conhecer pela narrativa histórica, pelos mitos, emblemas, monumentos, documentos e sinais, conforme Le Goff(1996).

A partir dessas considerações, estamos nos propondo a analisar e reelaborar com questões que se colocam como pressupostos que sustentam o trabalho de análise da construção da identidade do gaúcho no Centro de Memória referido. Desse modo, tomamos inicialmente a questão da memória relacionada à linguagem.

\section{MEMÓRIA}

Ao percorrermos a literatura específica da história (LE GOFF, 1996) nos deparamos com a história da memória, os enfoques que a questão vem recebendo desde a antigüidade greco-romana até a atualidade. São importantes os percursos que se mostram, pois é a partir deles que podemos delinear nosso objeto de estudo. É no encontro de uma memória com a atualidade que o novo se institui. Entretanto não nos ocuparemos em retomar tais percursos, mas apenas em deixar clara a concepção de memória que adotaremos. Em princípio, estamos entendendo, com Indursky \& Campos (2000, p. 12), que

a memória é um referencial vivo na construção das identidades, pois, em sua capacidade de filtrar e manter o sentido, atua por meio de seus processos e efeitos, os quais podem ser tanto 
de lembrança, de redefinição e de transformação quanto de esquecimento, de ruptura e de negação do vivido e do já dito. Se a memória é, portanto, um fator inerente à construção de identidade, o discurso é o espaço de conhecimento e de interação através do qual o ser humano se faz sujeito, inscrevendo-se no campo da prática social, que é eminentemente histórica.

Com isso encaminhamos nossa reflexão acerca das relações entre memória, história e linguagem.

\section{História e Memória}

No horizonte teórico em que nos situamos, a linguagem é vista como simbolizadora/constituidora da realidade, mas num movimento que coloca em cena sujeito, ideologia e história. Quando nos referimos à história estamos concebendo-a numa perspectiva de movimento, de ordem que organiza de modo contingente a própria realidade. A ordem da história enquanto mundo, material constitutivo que representa de modo simbólico a materialidade dos processos sociais. A história é dotada de propriedades que organizam a constituição dos fatos, na concepção materialista histórica. De acordo com Henry (1994, p. 29-54), as características próprias que a história tem afetam a língua e são a possibilidade das ciências. Ao opor concepções acerca da posição da história no contexto das ciências sociais, mostra que a ordem da história trabalha constituindo as ciências e seus objetos. Nesse sentido ela dá cientificidade à explicação dos processos discursivos.

Trazendo essa ordem para o acontecimento discursivo, podemos dizer que ela representa uma trama de fios que são trazidos da memória pelo movimento inapreensível. Movimento dotado de contradições e que constrói o emaranhado de fios de onde são tecidos os vários sentidos do mesmo fato histórico ou da mesma palavra. Aqui entra então a questão da memória, pois o que é trazida à lembrança vem de uma memória que se atualiza e se ressignifica a cada retomada. Dessa forma, aquilo que se denomina memória coletiva já resulta de retomadas intermináveis no arquivo da vida das sociedade, onde continuidades e rupturas se sucedem.

A memória coletiva, de acordo com Pierre Nora, (apud LE GOFF, 1996, p. 472) "é o que fica do passado no vivido dos grupos ou o que os grupos fazem do passado". Precisamos entender, entretanto, que o que fica do passado não foi selecionado por mero acaso, mas sim sob efeitos ideológicos e imaginários. Nesse sentido Le Goff (idem, p.426), ao mostrar as contribuições que a psicologia e a psicanálise acrescentaram aos 
estudos da memória individual, diz

a memória coletiva foi posta em jogo de forma importante na luta das forças sociais pelo poder. Tornarem-se senhores da memória e do esquecimento é uma das grandes preocupações das classes, dos grupos, dos indivíduos que dominaram e dominam as sociedades históricas. Os esquecimentos e os silêncios da história são reveladores desses mecanismos de manipulação da memória coletiva.

Nesse sentido, podemos pensar a memória nos seus efeitos silenciadores, ou seja, aquilo que é trazido à lembrança faz com que outras versões de um mesmo acontecimento histórico sejam silenciadas. Le Goff diz isso quando afirma que a memória pode negar a experiência temporal e a história. A memória coletiva está sempre submetida à hegemonia do poder, especialmente do Estado, uma vez que esse agrupa nos seus Aparelhos Ideológicos de Estado -AIE - (ALTHUSSER, 1992), todos os meios para constituir ou destituir a memória coletiva fazendo-a oscilar entre a lembrança e o esquecimento, conforme as posições assumidas à frente do poder Estatal. Podemos exemplificar isso com questões do cotidiano da guarda da memória. Por que em certo momento se decide que é necessário preservar, guardar determinados documentos ou monumentos e não outros? Essas decisões tomadas e levadas a efeito pelo aparato Estatal ou por instituições aparentemente não ligadas a ele nos confirmam que a memória coletiva é uma construção. Le Goff (1996, p. 473) nos chama atenção para a relação entre história, memória e constituição da memória coletiva. $\mathrm{O}$ autor diz

não podemos esquecer os verdadeiros lugares da história, aqueles onde se deve procurar, não a sua elaboração, não a produção, mas os criadores e os denominadores da memória coletiva: "Estados, meios sociais e políticos, comunidades de experiências históricas ou de geração, levadas a constituir seus arquivos em função dos usos diferentes que fazem da memória".

Ele nos aponta para a necessidade de olharmos os documentos/ monumentos que constituem a memória coletiva considerando sempre as condições em que os arquivos que guardam tais peças foram produzidos. Entra aqui então a consideração àquilo que, em Análise de Discurso, responde pela possibilidade de um mesmo enunciado ter múltiplos sentidos. Estamos tratando das condições de produção. A determinação das mesmas é de suma importância para que possamos compreender os significados da memória coletiva relacionada a um determinado contexto. Outra questão que se apresenta como crucial é o fato de que a simbolização é que permite a inscrição dos fatos nas redes de memória. Não há realidade sem que o simbólico opere sobre os acontecimentos. Por outro lado, a linguagem, 
veículo essencial da simbolização, está transpassada pela subjetividade e a ideologia, daí por que termos que tomar sempre documento/monumentos constituidores da memória coletiva como dotados de múltiplas possibilidades significantes. Desse modo, podemos nos remeter para a teoria do discurso e examinarmos nela o modo como a memória discursiva opera na constituição das redes de memória.

\section{MEMÓRIADISCURSIVA}

Memória discursiva recebe em $\mathrm{AD}$ um tratamento que a coloca muito relacionada à questão do discurso político. Courtine (1981), ao tratar sobre o discurso comunista dirigido aos cristãos, traz da arqueologia das idéias de Foucault a noção de que uma memória coletiva permeia a enunciação. Em Courtine (1981, p. 51-53) há uma formulação acerca da memória discursiva que faz pensar essa última como retorno das relações imaginárias do sujeito com o real sócio-histórico. Diz Courtine, referindose a um acontecimento político onde a irrupção da memória histórica vem produzir efeitos de sentido antagônicos:

toda a produção discursiva que se efetua dentro de condições determinadas duma conjuntura remete em oscilação, faz circular as formulações anteriores já enunciadas... vem romper, pela lembrança duma forma de ritual que preside a enunciação dum discurso político, como um efeito de memória na atualidade de um acontecimento sob uma forma de retorno da contradição dentro do diálogo.

Ainda que Courtine direcione a noção de memória discursiva para o discurso político, ele a coloca como pertinente a toda produção discursiva, pois mostra a relação entre interdiscurso e tempo curto da atualidade de uma enunciação, fazendo ver desse modo que a memória é condição de existência do acontecimento discursivo.

É nessa relação que sujeito e historicidade discursivamente constituídas têm o ponto de encontro. A memória discursiva se constitui como atravessamento do interdiscurso sobre si mesmo, uma vez que ele funciona determinando isso que podeldeve ser dito ou isso que não pode/não deve ser dito e está constituído pelo conjunto de saberes de uma FD. Desse modo, os efeitos de memória nem sempre serão o de retorno do dito em outro lugar, mas poderão ser de apagamento, esquecimento da memória para que a atualidade produza sentido numa determinada condição de produção.

Courtine (1981, p. 51-53) ao fazer indagações sobre o modo como a categoria da memória opera no interior de uma formação discursiva - FD 
reenvia a questão ao âmbito do enunciado [E], mostrando que a memória discursiva atua no interior da FD numa estreita relação entre interdiscurso/ intradiscurso. $\mathrm{O}$ interdiscurso fornecendo os elementos que constituem a memória e o intradiscurso lhes dando existência pela atualização num tempo curto de enunciação, o que denomina efeito de memória.

A indagação de Courtine (idem, p. 53) acerca do modo como se dá a lembrança, a repetição, a refutação ou mesmo o esquecimento dos elementos de saber que são enunciados?, tem, na análise do discurso comunista dirigido aos cristãos, dois caminhos indissociáveis possíveis: a repetição e a comemoração. Ambos, naturalmente submetidos, no processo discursivo, aos efeitos imaginários/ ideológicos.

Repetição tem relação com o retorno do já-dito. A inserção do enunciado [E] na formulação. A memória respondendo pelo movimento parafrástico. A comemoração remete ao plano do reformulado, do repetido, relembrado que se reinscreve no interdiscurso. A comemoração, entendemos, como efeito da tensão entre o já-dito e o dito na formulação. Representa a atualização da memória que retorna ressignificada pelo encontro com uma atualidade. A comemoração mesmo do retorno daquilo que não foi apagado. Em analogia, a isso que se diz sobre o discurso podemos pensar no que representam as festas, as comemorações de datas significativas num grupo social para manter e atualizar a memória coletiva. Cada nova edição da festa novos elementos podem se inscrever na rede de memória, assim como podem ocorrer rupturas e a fundação de novas redes. Há sempre a possibilidade de surgimento do novo junto com a repetição do velho.

Os dois processos básicos, paráfrase e polissemia, mantêm então estreita relação com a memória discursiva, assim como as práticas sociais respondem pela lembrança ou esquecimento de fatos da memória coletiva. Os efeitos de memória são constitutivos do acontecimento, sejam eles de esquecimento ou de lembrança (COURTINE, idem). Uma lembrança que pode apresentar-se dissimulada, mas recuperável pela análise com recurso à memória discursiva.

Nesse aspecto, Indursky (1997, p. 196-198), ao tratar sobre a heterogeneidade discursiva, mostra que o dizer, ainda que aparente absoluta homogeneidade, pode ter descoberta suas relações com o saber historicamente constituído pela categoria da memória discursiva. Nós ousamos dizer que a memória coletiva, simbolizada nos documentos/monumentos, festas, práticas sociais também traz uma heterogeneidade que pode ser desvelada a partir de diferentes gestos analíticos.

Retomamos aqui Courtine (1981, p. 51-53) para trazer o fato de 
que a memória discursiva produz efeitos de sustentação de uma posição, tanto pela lembrança quanto pelo esquecimento. E, a história, enquanto ciência que se ocupa da memória, também faz esse movimento duplo permitindo a lembrança ou o esquecimento daquilo que se inscreve ou não nos arquivos que guardam a memória coletiva.

\section{O FESTIIVAL NATIVISTA E A GUARDA DA MEMÓRIA}

Temos entendido que as músicas (letras) dos festivais nativistas fazem parte do movimento de preservação da memória do gaúcho. Movimento que faz ressoar o Regionalismo iniciado por Gilberto Freire em 1926, a partir do Manifesto Regionalista. Esse manifesto pode ser considerado como discurso fundador do regionalismo que passa a ser retomado em diferentes estados do País. No Rio Grande do Sul, o movimento toma corpo a partir da década de 40, com a fundação do CTG 35 . Ainda que o surgimento do CTG esteja relacionado à necessidade de um grupo de estudantes vindos da oligarquia rural de vivenciarem, no meio urbano, a cultura campeira, ele também é um marco da institucionalização do regionalismo e do tradicionalismo, no Estado. Os dois estão associados, uma vez que a consolidação de um depende do outro.

O manifesto propunha a reorganização do país alicerçada em valores regionais tradicionais. Essa seria a forma de proteger o poder aristocrático rural que se via ameaçado pela constante urbanização do país, atribuída à influência do industrialismo capitalista norte-americano, largamente dominado pela idéia de que o que é bom para o norte-americano deve ser bom para todos os outros povos da América (OLIVEN, 1990, p.70). O objetivo era mesmo manter o "status quo" inalterado, pois trata-se de um movimento que não exalta a inovação que atualizaria a cultura brasileira em relação ao exterior, como fez o Movimento Modernista (1922) mas sim preserva a tradição, inclusive de regiões economicamente atrasadas. Cada estado do País passa a vivenciar o movimento promovendo a adesão da população a práticas culturais que, muitas vezes, vêm simbolizar condições antagônicas àqueles que participam de tais práticas.

No Rio Grande do Sul, nas três últimas décadas, os festivais de música nativista têm sido a prática que chama cidadãos urbanos e rurais para trabalharem pela preservação de uma memória que se quer coletiva. Em projeto de pesquisa institucional temos nos ocupado da análise das letras de festival nativista que já está na vigésima segunda edição. O que temos vislumbrado confirma a existência de uma intenção de preservar a memória via retomada de significados que se atualizam construindo novos 
efeitos de sentido, mas onde ressoa sempre a tradição.

Tomamos então um pequeno recorte feito a partir da análise do arquivo de canções da Coxilha Nativista, edição de 1999 e, a título de exemplo, vejamos como o léxico coloca em circulação aquilo que deve manter-se como parte da memória coletiva. Na canção ...Da fé campesina se dá o entrelaçamento do discurso religioso com a da tradição gaúcha como forma de produzir efeitos de sentidos pretendidos mas não garantidos. Em:

Prenda Maria do Céu

Mãe do "piazinho Jesus"

Protege a todo o rincão

E ao derramar tua luz

Não te esqueças do peão...

O religioso e o gauchesco constroem uma unidade mas mantémse a preponderância da tradição uma vez que prenda e piazinho, ao trazerem o discurso religioso, reconstroem no imaginário coletivo figuras divinas personificadas como gaúchas. Também a abrangência e o objeto de proteção de Maria ficam restritos ao território e ao homem gaúcho, e o rincão e o peão que devem receber tal proteção.

A seleção lexical para composição dos versos traz sempre à lembrança de modo insistente uma memória que, num movimento deliberada, tenta ser solidificada. Os termos usados são próprios da indumentária, do espaço das lides do homem do campo.

Nesse sentido a heterogeneidade do discurso, ao mobilizar e fazer entrecruzarem-se diferentes formações discursivas, aponta para efeitos de sentido de rememoração, de presentificação de uma realidade que não parte do cotidiano de todo cidadão rio-grandense, mas busca fazer com que todos se mantenham presos a uma rede de memória que simboliza significados importantes a um determinado grupo social.

\section{CONSIDERAÇÕES FINAIS}

A memória coletiva parece ser administrável no seu processo de constituição, quando observada no cotidiano dos fatos que rememoram a toda hora uma tradição que se busca manter usando de gestões artísticas, administrativas e políticas. A ilusão de administrar a memória dá ao senhores guardiões da tradição, através dos festivais nativistas, uma alento. Nesses eventos toda vez que o "pampa, suas lides, seus peões e chinocas" são lexicalizados e musicados, retorna à lembrança um passado carregado de outros sentidos os quais se tenta ignorar, entretanto o arquivo pode recolhêlos sem submetê-los a esses guardiões que habitam os pampas cobertos pelo poncho dos interesses que a canção não enuncia. 


\section{BIBLIOGRAFIA}

ALTHUSSER, Louis. Aparelhos ideológicos do Estado. 2 ed. Rio de Janeiro, Graal, 1992.

CAMPOS, Maria do Carmo \& INDURSKY Freda.(org.) Discurso, memória, identidade. Porto Alegre, Sagra-Luzzato,2000.

COURTINE, Jean Jacques. Analyse du discours Politique (le discours communiste adressé aus chrétiens). Paris, Larousse, Langages, n.62, juin 1981.

FOUCAULT, Michel. Arqueologia do saber. 4 ed. Rio de Janeiro, Forense Universitária, 1995.

HENRY, Paul. A história não existe? In: ORLANDI, Eni P. (org.) Gestos de leitura: da história no discurso. Campinas, Ed. da UNICAMP, 1994.

INDURSKY, Freda. A fala dos quartéis e outra vozes. Campinas, Ed. da UNICAMP, 1997.

LE GOFF, Jacques. História e memória. 4 ed. Campinas, Ed. da UNICAMP, 1996.

OLIVEN, Ruben George. Que país é este? A (des) construção da identidade nacional. In: SOUSA, Edson. (org.). Psicanálise e colonização: Leituras do sintoma social no Brasil. Porto Alegre, Artes e Ofícios, 1999.

PÊCHEUX, Michel. Ler o arquivo hoje. In: ORLANDI, Eni P. (org.) Gestos de leitura: da história no discurso. Campinas, Ed. da UNICAMP, 1994. 